\title{
Spatial identification of conservation priority areas for urban ecological land: An approach based on water ecosystem services
}

Jian Peng; An Wang; Lingwei Luo; Yanxu Liu; Yi’na Hu; Jeroen Meersmans; Jiansheng $\mathrm{Wu}$

1. Jian Peng

Corresponding author

Laboratory for Earth Surface Processes, Ministry of Education, College of Urban and Environmental Sciences, Peking University, Beijing 100871, China.

Tel.: +861062750926

Email: jianpeng@urban.pku.edu.cn

\section{An Wang}

Key Laboratory for Environmental and Urban Sciences, School of Urban Planning \&

Design, Shenzhen Graduate School, Peking University, Shenzhen 518055, China.

Email: 442121809@qq.com

3. Lingwei Luo

Laboratory for Earth Surface Processes, Ministry of Education, College of Urban and Environmental Sciences, Peking University, Beijing 100871, China.

Email: mine@pku.edu.cn

4. Yanxu Liu

State Key Laboratory of Earth Surface Processes and Resource Ecology, Faculty of

Geographical Science, Beijing Normal University, Beijing 100875, China.

Email: yanxuliu@bnu.edu.cn 


\section{Huilei Li}

Laboratory for Earth Surface Processes, Ministry of Education, College of Urban and Environmental Sciences, Peking University, Beijing 100871, China.

Email: lihuilei@pku.edu.cn

6. Yi'na $\mathrm{Hu}$

Laboratory for Earth Surface Processes, Ministry of Education, College of Urban and Environmental Sciences, Peking University, Beijing 100871, China.

Email: huyina@foxmail.com

7. Jeroen Meersmans

School of Water, Energy and Environment, Cranfield University, Cranfield, MK43

0AL, United Kingdom.

Email: Jeroen.Meersmans@cranfield.ac.uk

8. Jiansheng $\mathrm{Wu}$

Key Laboratory for Environmental and Urban Sciences, School of Urban Planning \& Design, Shenzhen Graduate School, Peking University, Shenzhen 518055, China.

Email:wujs@pkusz.edu.cn 


\section{Spatial identification of conservation priority areas for}

2 urban ecological land: An approach based on water ecosystem services in the pro- cess of urbanization has been the focus of land degradation researches in urban areas. Urban ecological land can be defined as the natural base on which a city relies to eco- logically survive. It closely links the social economy with the natural ecoenvironment, providing an important integrated approach to resolve the contradiction

10 between urban expansion and natural ecosystems conservation in the process of 11 urbanization. The research question addressed in this study is how to accurately identify 12 the conservation priority areas for urban ecological land. Taking Zhuhai City, located 13 in China, as an example, an approach based on seven kinds of water ecosystem services 14 was put forward, combining social demand and natural supply for the services to 15 determine service targets and conservation priority areas. The results showed that the conservation priority areas in Zhuhai City covered $868 \mathrm{~km} 2$, accounting for $51.03 \%$ of the total land area, which were mainly covered by woodlands or paddy fields and fish ponds. In addition, by synthesizing ecological importance and ecological sensitivity,

19 management zones for urban ecological land were delineated, including

$20510 \mathrm{~km} 2$ of primary control areas and $358 \mathrm{~km} 2$ of secondary control areas. In the

21 supply and demand view of water ecosystem services, this study put forward an integrated ecosystem- based approach for conservation priority area identification of

23 urban ecological land, aiming to prevent land degradation and achieve urban ecological 24 sustainability.

25 Keywords: conservation priority areas, spatial identification, urban ecological 


\section{Introduction}

Since the beginning of this century, rapidly increased population and intensified utilization of land resource have caused continuous degra- dation of land as well as ecosystem deterioration at the global scale, threatening food and ecological security on the mid to long term (Capps, Bentsen, \& Ramírez, 2016; Ng, Leung, Cheung, \& Fang, degradation research should not only measure or predict the drivers of land degradation but, more importantly, also focus on the prevention of land degradation, especially in developing regions. As a significant trend of human development, urbanization has Li, Peng, Liu, \& Hu, 2017; Y. Li, Sun, Zhu, \&Cao, 2010; Qiu, Song, \& Li, 2017). Urban expansion would often trans- form the original natural ecosystem into impervious surface with fun- damental change of material and energy flows (Alberti, 1999) and thus bringing significant degradation of habitat quality (Bajocco, Angelis, Perini, Ferrara, \& Salvati, 2012; W. Li, Wang, Li, \& Liu, 2017; Oliveira, Tobias, \& Hersperger, 2018). The quantity and quality changes of eco- system services have led to urban ecoenvironmental problems such as urban heat islands, air pollution, and flood disasters (Cheng, Chen, Sun, \& Kong, 2018; H. Fu \& Chen, 2017; J. Li et al., 2011). As the most fundamental material basis for the survival and devel- opment of human society, land provides the basic spatial carrier for human activities (Felipe- Lucia, Comín, \& Bennett, 2014; Ólafsdóttir \& Júlíusson, 2015). Because land use is the most predominant carrier for human's influence on natural ecosystems, human society is closely linked with natural ecosystems through the inherent connection between land 
use and land cover (B. B. Lin et al., 2018; Runfola \& Pontius, 2013; Thomas, Sporton, \& Perkins, 2015). Urban ecological land, as one functional type of land use, can be defined as the natural base on which a city relies to ecologically survive (Peng, Zhao, Guo, Pan, \& Liu, 2017). It not only maintains the ecological cycle and biodiversity but also provides the ecosystem services to satisfy human demands (Bergsten, Galafassi, \& Bodin, 2014; McPhearson, Kremer, \& Hamstead, 2013). Thus, urban ecological land is fundamental to urban ecological sustainability, and effectively protecting urban ecological land has been considered as one of the key issues in combating land degradation in urbanizing areas.

With increasing global awareness about ecological security and sustainability (Q. Lin, Mao, Wu, Li, \& Yang, 2016; Peng, Yang, et al., 2018; Runfola et al., 2017; Zhang, Peng, Liu, \& Wu, 2017), research on identification and protection of important urban ecological land has flourished over recent years. For example, the method of ordered weighted averaging was used to identify priority areas for forest resto- ration with the objective to improve water resource conservation (Vettorazzi \& Valente, 2016); optimal conservation planning of multiple hydrological ecosystem services was conducted considering land use and climate change (M. Fan, Shibata, \& Wang, 2016); the conservation and management of urban green space were reviewed considering the biodiversity of terrestrial fauna species (opucki \& Kiersztyn, 2015); green infrastructure was designed on the premise of spatial conservation prioritization (Snäll, Lehtomäki, Arponen, Elith, \& Moilanen, 2016); and urban green infrastructure planning was explored combining the conservation of biodiversity and the delivery of ecosystem services (Capotorti, Vico, Anzellotti, \& Celesti- Grapow, 2016). Among the abovementioned studies, whether the restoration and protection of urban ecological land, the identification and management of urban green space, or the planning and 
design of urbangreen infrastructure were all based on prioritizing the protection of ecologically important areas. Given the huge human pressure on natu- ral ecosystems in the process of rapid urbanization, the protection of most important ecological land units with a limited investment should be considered as a basic principle of urban ecological management. This is crucial for securing the welfare of future generations through long- term ecosystem management.

Inherently linking natural ecosystem process with human well-being (Kong et al., 2016; C. Li et al., 2015; Zheng et al., 2016), ecosystem services provide an effective approach for assessing con- servation needs and spatially identifying the priority areas for urban ecological land. Water- related ecosystem services, referred to as the "water ecosystem services" (Yang, Zhang, Li, \& Wu, 2015), are considered as the core services to meet urban residents' demands. Water ecosystem services can strongly influence a wide range of other (nonwater) ecosystem services and thus dominate the most important feedback mechanisms between man and nature. As water ecosystem services can also be quantitatively measured and monitored (Farooqui, Renouf, \& Kenway, 2016; Martin- Ortega, Ojea, \& Roux, 2013; Moore \& Hunt, 2012; Mulatu, Veen, \& Oel, 2014), they meet the representa- tive, comprehensive, and threshold requirements for identifying con- servation priority areas for urban ecological land. Consequently, water ecosystem services can be considered as an effective tool to identify the conservation priority areas for urban ecological land.

Zhuhai City is located in the lower reaches of the Pearl River Basin, the third largest drainage basin in China. The city is built near the river, covering natural habitat for water- related flora and fauna. As a result, natural ecosystems as well as the daily activity of local res- idents are closely linked with water. Thus, Zhuhai City is the ideal study area for identifying conservation priority areas in view of water ecosystem 
100 services. Furthermore, as one of the earliest special eco- nomic zones established in

101 China, Zhuhai City is ushering in a new round of urban construction against the 102 background of new phase of intensified urbanization. Consequently, it is most urgent 103 that the city identifies the conservation priority areas for urban ecological land based 104 on water ecosystem services. The objectives of this study are (a) to establish a 105 framework for measuring and mapping water ecosystem services; (b) to identify 106 conservation priority areas for urban ecological land based on water ecosystem services; 107 and (c) to delineate management zones for urban ecological land considering both 108 ecological importance and sensitivity.

\section{$110 \quad 2$ Materials and methods}

\section{$111 \quad 2.1$ Study area and data sources}

112 Zhuhai City is located south of Pearl River Delta and along the west side of the Pearl

113 River estuary (Figure 1), covering the estuary of the Modaomen, Jitimen, Hutiaomen, 114 and Yamen water systems in the Pearl River Basin $\left(113^{\circ} 03^{\prime}-114^{\circ} 19^{\prime} \mathrm{E}, 21^{\circ} 48^{\prime}-\right.$ $\left.11522^{\circ} 27^{\prime} \mathrm{N}\right)$. The city is characterized by wet climate condition, with an average annual 116 rainfall amount of 2,042 $\mathrm{mm}$. However, the rainfall is unevenly distributed during the 117 year with remarkably less over the winter and spring and more over the summer and 118 autumn. More precisely, the precipitation tends to be concentrated in the flood season 119 from May to June, which accounts for more than $30 \%$ of the total annual rainfall. 120 Xijiang River, the main stream of the Pearl River, is divided into a plurality of tributaries 121 as it enters Zhuhai City in the northern part of Doumen District. The tributaries then 122 merge into three main streams and discharge into the South China Sea from north to 123 south, where disasters such as extensive flooding are occurring frequently. 
As a result, soil retention, runoff reduction, and flood regulation are selected as key regulating services in this study. In addition, water pollution is a serious issue in this city, as drinking water sources often contain chemical pollutants, and most groundwater is also contaminated by heavy metal ions. Thus, water protection and water conservation are selected as key provisioning services in the view of water quality and quantity, respectively. Moreover, as a coastal city, there are various kinds of water landscapes, including a large amount of waterfront parks. Accordingly, close- to-

131 water recreation and distant- water appreciation are selected as key cultural services. $\mathrm{km} 2$ of sea area. Land use types in Zhuhai City mainly include woodland, paddy field

134 and fish pond, and construction land, accounting for $28.24 \%, 26.44 \%$, and $23.67 \%$ of

135 the total land area, respectively. Woodland and construction land are interdependently 136 distributed, with a large amount of woodland distributed within or around the built- up 137 areas. Paddy field and fish pond are mainly dis- tributed along the water system and the 138 reservoirs. Furthermore, there are also almost $200 \mathrm{~km} 2$ of unused land and a small 139 amount of water bodies, dry croplands, and grasslands.

140 The data of this study mainly included two categories:

141 Spatial data. Land cover data for the year 2010 from the Globeland30- 2010 dataset 142 were provided by the Chinese Basic Geographic Information Center 143 (www.globallandcover.com/ GLC30Download/ index.aspx). Digital elevation model 144 data SRTM90m (CGIAR- CSI) were provided by the Computer Network Information 145 Center of the Chinese Academy of Sciences (http://www.cnic.cas.cn/ zcfw/ sjfw/ 146 gjkxsjjx/ ). Normalized difference vegetation index data were obtained from the 147 MODIS MOD13Q1 product with spatial resolution of $250 \mathrm{~m}$, provided by the U.S. 148 Geological Survey (https:/ / lpdaac.usgs.gov/ dataset_ discovery/ modis/ 
modis_products_table/ mod13q1). Soil type data were the 1:1,000,000 soil dataset of

150 Western Environmental and Ecological Science Data Center of the Chinese Academy

151 of Sciences. Meteorological data, including precipitation, temperature, and sunshine,

152 were from the Chinese Meteorological Data Service Platform (http:/ / data.cma.cn/ ).

153 Urban and regional planning reports, which were collected from the official websites

154 of the governmental departments of Zhuhai City, include the following documents:

155 urban master planning, overall planning for land utilization, geological disaster

156 protection planning, water supply engineering scheme, water resources comprehensive

157 planning, green space system planning, and the major function- oriented zoning.

\section{$158 \quad 2.2$ Research framework}

159 aking ecological land as the spatial carrier of ecosystem services and integrating the 160 supply and demand of ecosystem services, a concep- tual framework of spatially 161 identifying conservation priority areas for urban ecological land was developed (Figure

162 2). First, seven kinds of water ecosystem services covering the three categories of 163 regulating, provisioning, and cultural services were selected in the study area, together 164 with mapping the supply of these services. Second, for each kind of water ecosystem 165 services, service targets were determined according to societal demand and natural 166 supply capacity. Third, based on the supply capacity of ecological land in terms of 167 ecosystem services, ecological land fulfilling the service target was identified. Finally, 168 all the identified ecological lands were overlapped using ArcGIS in order to spatially 169 identify conservation priority areas for urban ecological land in Zhuhai City. In addition, 170 by synthesizing ecological importance and sensitivity, management zones for urban 171 ecological land were delineated. 


\subsection{Spatial identification of ecosystem service land}

173

\section{(1) Regulating service land}

Regulating services refer to the services and benefits derived from the regulatory effect on ecosystem processes. Water regulation services achieve their regulatory effect by controlling hydro-ecological processes, including the services of soil retention, runoff reduction, and flood regulation.

Soil erosion reflects the degree of soil loss, which is related to rainfall erosivity, soil erodibility, slope length, slope steepness, crop management and support practices (Guo et al., 2018; Liu et al., 2010). Ecological land with high soil retention service was identified by calculating the difference of soil erosion amounts from areas that included and excluded ecological land. According to the degree of soil erosion in Zhuhai City and its hazard level, the mild soil erosion rate $\left(2500\right.$ tons $\cdot \mathrm{km}^{-2} \cdot \mathrm{a}^{-1}$ or more) was selected as the service target of soil retention. Ecological land with soil retention service exceeding the target amount was identified as the service land of soil retention.

The revised version of the Universal Soil Loss Equation, i.e. RUSLE (Galdino et al., 2016), was used to calculate the total amount of soil retention (B):

$$
\mathrm{B}=\mathrm{R} \cdot \mathrm{K} \cdot \mathrm{L} \cdot \mathrm{S} \cdot(1-\mathrm{C}) \cdot \mathrm{P}
$$

Where $R$ is the rainfall erosivity factor, calculated using Wischmeier's empirical formula ( $\mathrm{Fu}$ et al., 2005); $K$ is the soil erodibility factor, calculated by the $\mathrm{K}$-value estimation method proposed in the EPIC model (Polyakov et al., 2007); $L$ is the slope length factor, calculated by an empirical formula that combines horizontal slope length and slope length index (Kinnell, 2010); $S$ is the slope steepness factor, calculated according to McCool's classic slope formula based on the gradient (Nakil \& Khire, 2016); $C$ is the crop management factor, obtained by the vegetation coverage, which 
can be calculated from the average annual NDVI; and $P$ is the support practice factor.

197 Referring to previous studies, the $P$ value of various types of land cover was determined

198 (Panagos et al., 2015; Taye et al., 2017).

199 To identify service land of runoff reduction, the Sponge City Construction 200 Technology Guide promulgated by the Ministry of Housing and Urban-Rural 201 Development of China was followed. According to the technology guide which was 202 based on a statistical analysis of the daily rainfall in 200 Chinese cities during 19832009, the runoff reduction target in Zhuhai City was set as 70\%, and the corresponding design rainfall was $25.2 \mathrm{~mm} \mathrm{hr}^{-1}$. In details, the main steps were as follows. Firstly, the runoff collection point in a catchment area was identified as the regulation control point after dividing catchment areas. Secondly, the demanding size of service land of runoff reduction was determined according to the runoff load in the catchment area and the regulating capacity of ecological land. Finally, based on the spatial location of the regulation control point and the demanding size of service land, the service land of runoff reduction was spatially identified.

211 The United States Soil Conservation Service (SCS) hydrological model was used to 212 calculate the runoff load (Ajmal et al., 2015). The model can reflect a wide range of 213 underlying factors, such as land use, soil type and pre-soil wetting conditions, as well 214 as the impact of human activities on rainfall runoff. Relatively few parameters are 215 required in the model.

$$
Q=\left\{\begin{array}{c}
\frac{(P-0.2 S)^{2}}{S+P-0.2 S}, \quad P>0.2 S \\
0, \quad P \leq 0.2 S
\end{array}\right.
$$

217 Where $Q$ is the runoff $(\mathrm{mm}), P$ is the total rainfall $(\mathrm{mm})$, and $S$ is a parameter 218 reflecting the effects of soil and water conservation. As a mean of measuring the value 219 of $S$, the SCS model was used, which has a dimensionless parameter called the curve 
number $(\mathrm{CN})$ based on physical features and soil types. It also defined the relationship between $\mathrm{S}$ and $\mathrm{CN}$ as follows:

$$
\mathrm{S}=254 \times \frac{100}{\mathrm{CN}-1}
$$

In this study, the original $\mathrm{CN}$ values for hydrological groups of soils were amended based on previous studies in Pearl River Delta (Fan et al., 2013; Lin et al., 2014; Xu et al., 2016). The runoff pattern under rainfall events was simulated using the SCS model, and thus the runoff of each catchment area was calculated to obtain the runoff load.

In flood regulation, what downstream cities such as Zhuhai can do is mainly manifested in two aspects, i.e. maintaining the smooth flow of the flood discharge channel and ensuring the rivers to access the floodplains. In this study, Laolao Creek,

230 Helao Creek, Hengkeng Waterway, Chifen Waterway, Luozhou Creek, Huangyang 231 River, Jintimen Waterway, Modaomen Waterway, and Tiansheng River, all of which connected Xijiang River and Pearl River estuary, were identified from more than 170 rivers in Zhuhai City as the main protected flood discharge channels. According to the green space system planning of Zhuhai City, a 100-m buffer zone on both sides of the

235 flood discharge channels was set as the flood avoidance area. Important flood discharge channels and the 100-m buffer zone were integrated as the service land of flood 237 regulation.

\section{(2) Provisioning service land}

239 Water provisioning services are the services that human obtains directly from natural 240 water resources, including the provision of drinking, industrial and agricultural water. 241 Ecological land plays a significant role in water provisioning services through 242 protecting and conserving water resources. The main water supply channels, water 243 intake points and water storage areas are the most vulnerable areas in the view of the 244 safety of urban water source. Thus, they were designated as water protection areas. 
Meanwhile, according to the relationship among rainfall, runoff and evaporation, urban ecological land characterized by high water conservation capacity was set as water conservation areas.

248 In order to specify the water protection areas more precisely, the water supply 249 engineering scheme of Zhuhai City was considered. It identified (i) the Modaomen 250 Waterway and Huangyang River as main sources of drinking water, (ii) the Hutiaomen 251 Waterway as the main source of industrial water, and (iii) the reservoirs in the middle 252 and western part of the city as auxiliary water sources. Furthermore, in the water 253 resources comprehensive planning of Zhuhai City, two levels of water protection area 254 were designated. The first level was set as the target of water protection, according to 255 the effect and cost of ecological land for protecting water sources. Subsequently, based on the set service targets, the following riparian areas were classified as water protection areas (Kingsford et al., 2011): (i) the rivers with main function of water supply, (ii) the water areas within $1500 \mathrm{~m}$ upstream and downstream of the five water intake points, and (iii) the land within 100 meters distance from the water intake points. In fact, 260 although ultimately aiming at the provisioning of water resource, criteria (ii) and (iii) 261 also refer to the highest service of water purification. In addition, all the 26 reservoirs in the city, as well as their corresponding catchment areas with the first-level protection were also classified as water protection areas.

264 For water conservation service, the conservation degree of rainfall by ecological land 265 was calculated through the relationship among water conservation and water 266 demanding. The relationship between regional annual water conservation $H$ and water 267 demanding $X$ is as follows:

$$
\mathrm{k} \cdot \mathrm{H}=\mathrm{X}
$$

$$
H=\alpha \cdot P
$$


where $k$ is the local water use efficiency, and $P$ is the average annual rainfall.

271 According to the water resources comprehensive planning of Zhuhai City, $k$ was set as

$27256 \%$ with $2042 \mathrm{~mm}$ for $P$, and $X$ was 440 million $\mathrm{m}^{3}$ including domestic, ecological

273 and agricultural demanding. As a result, the degree of conservation $(\alpha)$ should reach

$27422.7 \%$, compared with the total rainfall.

275 To remain consistent with runoff reduction, assuming $25.2 \mathrm{~mm}$ of rainfall in 1 hour 276 as the representative rainfall event, the degree of conservation in this rainfall event 277 should also be $22.7 \%$. Considering the area of Zhuhai City, such a representative rainfall 278 event would produce a rainfall amount of $42.56 \times 10^{6} \mathrm{~m}^{3}$, and the amount of water 279 conservation should reach $9.67 \times 10^{6} \mathrm{~m}^{3}$. In a single rainfall event, for ecah spatial unit, 280 assuming that the amount of water conservation is $x$, the rainfall is $p$, the runoff is $q$, 281 and the evaporation is $z$, the following water balance equation will exist:

$$
\mathrm{x}=\mathrm{p}-\mathrm{q}-\mathrm{z}
$$

Furthermore, water conservation capacity for ecological land was calculated using

284 SCS model as mentioned above. The ecological lands with the highest conservation 285 capacity were selected as water conservation area, meeting the demanding amount of 286 water conservation.

\section{(3) Cultural service land}

288 Cultural ecosystem services refer to the non-material benefits people obtain from 289 natural ecosystem. As a kind of ecological land, water body can also fulfill important 290 cultural services. In this study, water-based recreation was regarded as the 291 representative of water-related cultural services, including both close-to-water recreation and distant-water appreciation. Water-based recreation relies on areas that

293 have recreation attraction. The important recreation areas in Zhuhai City were extracted 294 as the basic evaluation units, including recreational rivers, natural and cultural heritage 
areas, nature reserves, scenic locations, urban parks, and greenways.

In terms of service land of close-to-water recreation, it should include not only water

297 bodies with recreation attraction, but also ecological land with high accessibility to the 298 water bodies. According to the water resources comprehensive planning of Zhuhai City, 299 water bodies with recreation attraction were extracted. Based on the extracted water 300 bodies, the usual distance that connects scenic spots, i.e. a five-minute walking distance 301 of $360 \mathrm{~m}$ (Bassett et al., 2000), was used to determine the buffer zone. These water 302 bodies and recreation areas within the buffer zone were identified as water recreation 303 areas.

304 To identify distant-water appreciation areas, recreation areas from which water 305 bodies could be watched with high frequency were considered. Taking the main water 306 bodies as watching objects, spatial pattern of watching frequency of these main water 307 bodies across the entire city was obtained using the sight analysis tool of GIS software. 308 More precisely, recreation areas with water-watching frequency above the average were 309 included in the cultural service land.

\section{$310 \quad$ 2.4 Partition control of urban ecological land}

311 A city is a coupled human and nature system, with great spatial heterogeneity in its 312 component and functioning. Ecological land is the spatial basis for provisioning 313 ecosystem services. However, for different kinds of ecological land, and even the same 314 kind of ecological land at different locations, their importance and sensitivity to 315 ecosystem services maybe be quite different. Partition control has become an effective 316 way in urban ecological land management. Ecological importance of urban ecological 317 land refers to the intrinsic ecological functions and services it undertakes, whereas 318 ecological sensitivity of urban ecological land can be defined as the sensitivity of the 
319 land to maintain ecosystem services under the impact of strong external disturbance 320 (Peng et al., 2015). Hence, through grading the ecological land according to ecological 321 importance and ecological sensitivity, and overlaying the two kinds of grading, a 322 partition management for urban ecological land could be conducted.

323 To quantify the ecological importance, the three maps of regulating service land, 324 provisioning service land, and cultural service land were overlaid in ArcGIS. And subsequently, the ecological importance of ecological land was graded into three levels, i.e. high importance, medium importance, and low importance, corresponding to the appearance in three, two, and one kind of service land maps, respectively.

When investigating the ecological sensitivity, urban areas, towns, villages, roads and railways were considered to quantify human threats on biodiversity using habitat quality module of InVEST, which helped to grade the sensitivity of ecological land.

331 InVEST model has been widely used to analyze the impact of human-induced 332 ecological threating on land cover, and further to evaluate habitat quality and its 333 degradation (Posner et al., 2016). The principle of ecological sensitivity evaluation is 334 as follows:

$$
\begin{gathered}
D_{x j}=\sum_{r=1}^{R} \sum_{y=1}^{Y_{r}}\left(\frac{w_{r}}{\sum_{r=1}^{R} w_{r}}\right) r_{y} i_{r x y} \beta_{x} S_{j r} \\
i_{r x y}=1-\left(\frac{d_{x y}}{d_{r \max }}\right)
\end{gathered}
$$

337 where $D_{x j}$ is the ecological sensitivity, $R$ is the number of sensitive source, $w_{r}$ is the 338 sensitivity weight, $Y_{r}$ is the pixel number of sensitive source, $r_{y}$ is the number of 339 sensitive source on each pixel, $i_{r x y}$ is the threating of sensitive source, $\beta_{x}$ is degree of 340 legal protection, $S_{j r}$ is the sensitivity coefficient, $d_{x y}$ is the sensitive distance, and $d_{r m a x}$ 341 is the maximum sensitive distance of sensitive source. Specifically, urban areas, towns 342 and roads were considered to exert higher threating on ecological land, whereas it was 
343 relatively small for villages and railways. In addition, dry croplands, paddy fields and

344 fish ponds as well as unused land were considered to be most sensitive to these threating,

345 followed by grassland, woodland and water body. (Table 1).

346 [Table 1 is here]

347 As the result of management zoning, primary and secondary control areas were 348 spatially identified through overlaying the maps of ecological importance and 349 ecological sensitivity. Using the method of natural break, ecological sensitivity of 350 ecological land could be divided into three levels, i.e. high sensitivity, medium 351 sensitivity, and low sensitivity. Then the management zones for urban ecological land 352 in Zhuhai City were delineated according to the combination of ecological importance 353 level and ecological sensitivity level. In detail, ecological land with high ecological 354 importance or high ecological sensitivity was identified as primary control area, 355 whereas the other part of conservation priority areas were identified as secondary 356 control areas.

\section{$357 \quad 3$ Results}

\subsection{Key areas supplying ecosystem services}

359 Through integrating the supply and demanding of ecosystem services, spatial 360 distribution of key areas supplying the demanded seven ecosystem services were

361 obtained (Figure 3). I This result showed that the soil retention service was mainly 362 distributed in mountainous areas characterized by abundant vegetation that could 363 effectively retain soil (Figure 3a). The runoff reduction service was concentrated in the 364 low-lying areas around the main water systems (Figure 3b), covering a total area of 128 365 $\mathrm{km}^{2}$ with the minimum and maximum patch area of 1 ha and 249 ha, respectively. The 
flood regulation service was chiefly distributed in riparian zone around major rivers with the potential to ameliorate or prevent flood disaster (Figure 3c). The water protection service covered a total area of $120 \mathrm{~km}^{2}$, locating around such water sources as rivers and reservoirs (Figure 3d). The water conservation service had an area of 444 $\mathrm{km}^{2}$, accounting for $26.10 \%$ of the total land area, and was mostly provided by

371 woodlands and paddy fields (Figure 3e). The water recreation service was located in areas adjacent to water body and contained all the offshore islands and the banks of the rivers (Figure 3f). The water appreciation service was concentrated in the high-lying areas, which had the topographical induced advantage of having a great sight potential

375 for attractive waterscape (Figure $3 \mathrm{~g}$ ).

$376 \quad$ [figure 3 is here]

\subsection{Conservation priority areas for urban ecological land}

Spatial distributions of the three categories of ecosystem service land were obtained through overlaying key areas of ecosystem services in the same category (Figure 4). As shown in Figure 4a, regulating service land was $547 \mathrm{~km}^{2}$, accounting for $32.16 \%$ of the total land area. Comprised of soil retention area, runoff reduction area, and flood regulation area, the regulating service land included the main mountain areas with high vegetation coverage, the major flood channels and floodplains, as well as the low-lying green areas distributed at the outlets of various sub-catchments. The area of

385 provisioning service land was $509 \mathrm{~km}^{2}$, accounting for $29.92 \%$ of the total land area. It contained $120 \mathrm{~km}^{2}$ of water protection area and $444 \mathrm{~km}^{2}$ of water conservation area, and was mainly distributed in water supply channels and water bodies, woodland in

388 mountain areas, and paddy fields in the plain (Figure 4b). The area of cultural service 389 land was $498 \mathrm{~km}^{2}$, accounting for $29.28 \%$ of the total land area. It was mainly located 
391 to the main water bodies, the cultural service land had the advantages of providing 392 water-related recreation and appreciation services.

393 [figure 4 is here]

394 Based on the relationship between ecological land and its ecological functions and 395 services, which was embodied in ecological processes, ecological land that met the 396 demanding targets of key ecosystem services was defined as conservation priority areas. 397 More specifically, through overlaying the regulating service land, provisioning service 398 land and cultural service land, the conservation priority areas of water ecosystem 399 services in the study area could be mapped (Figure 5). After removing the overlapped 400 ones among the three kinds of service land, the conservation priority areas for urban 401 ecological land in Zhuhai City were determined to be $868 \mathrm{~km}^{2}$, accounting for $51.03 \%$ 402 of the total land area. They were mainly composed of woodlands in mountain areas, 403 water bodies and cropland in the plains.

404 [figure 5 is here]

\subsection{Management zoning for urban ecological land}

406 As shown in Figure 6a, there was distinct spatial agglomeration for ecological 407 importance grades of conservation priority areas in Zhuhai City. In total an area of 243 $408 \mathrm{~km}^{2}$ (accounting for $28 \%$ of the conservation priority areas) was contained in the maps 409 of three kinds of service land, and hence, it was classified as area of high ecological 410 importance. These areas included two parts: one was found in the mountainous areas 411 with dense vegetation coverage, referring to the ecosystem services of soil retention, 412 water conservation, and water appreciation. The other one was mainly located across 413 the main rivers, representing the ecosystem services of water recreation, water 
414 protection, runoff reduction and flood regulation. Furthermore, the medium and low 415 ecologically important areas, i.e. contained in two and one kind of service land map, 416 counted to be $241 \mathrm{~km}^{2}$ and $384 \mathrm{~km}^{2}$, respectively. Low ecological importance area was 417 mainly composed of woodlands in the plains providing water conservation service, 418 paddy fields, fish ponds and beaches for runoff reduction service.

419 Ecological sensitivity of conservation priority areas was also quantified (Figure 6b). 420 In total an area of $245 \mathrm{~km}^{2}$ was identified as areas of high ecological sensitivity, 421 accounting for $28.23 \%$ of the conservation priority areas. These areas mainly covered 422 the runoff reduction land and water conservation land close to the urban areas in the 423 plain, as well as the locations along the periphery of Fenghuang Mountain, Huangyang 424 Mountain and Jiangjun Mountain. The areas of medium and low ecological sensitivity counted to be $249 \mathrm{~km}^{2}$ and $374 \mathrm{~km}^{2}$ respectively, both concentrated in the central part of mountain areas as well as islands far away from human activities.

427 By synthesizing ecological importance and sensitivity, $510 \mathrm{~km}^{2}$ of primary control 428 areas were identified, accounting for $58.76 \%$ of the conservation priority areas for 429 ecological land. These primary control areas were mainly concentrated in mountains 430 and islands, or runoff reduction land, with high ecological importance or severe human 431 disturbance. The secondary control areas covered an area of $358 \mathrm{~km}^{2}$, accounting for $43241.24 \%$ of the conservation priority areas for ecological land. It was mainly distributed 433 in the plains with lower ecological importance or sensitivity. Generally speaking, the 434 primary control areas should implement the strictest ecosystem protection. For example, 435 any construction activities, unrelated to a specific ecological protection, scientific 436 research or educational purpose, should be prohibited. Population growth should be 437 strictly controlled through the gradual relocation of permanent residents out of the areas 438 (Gong et al., 2017). Besides strictly controlling human interference with original 
439 landform, vegetation and water system, ecological protection, restoration and 440 construction should also be implemented by means of biological engineering measures 441 (Bai et al., 2018). On the contrary, human activities such as infrastructure construction 442 could be permitted in the secondary control areas, under the premise of non-increasing 443 the risk of environmental pollution or ecological degradation.

$444 \quad$ [figure 6 is here]

\section{Discussion}

\subsection{Spatial differentiation of conservation priority areas}

The spatial differentiation of conservation priority areas in Zhuhai City was analyzed in the view of land use type and elevation, which were highly correlated with area proportion of conservation priority areas. Seven land use types in the study area were considered, i.e. construction land, woodland, water body, dry cropland, paddy field and

451 fish pond, grassland and unused land. Through comparing the area proportion of land use types in conservation priority areas, and that of land use types identified as conservation priority areas, land use differentiation of conservation priority areas could

454 be analyzed (Figure 7). The results showed that the main land use types in the 455 conservation priority areas were woodland $\left(430.2 \mathrm{~km}^{2}\right)$, and paddy field and fish pond $456\left(175.1 \mathrm{~km}^{2}\right)$, accounting for $49.56 \%$ and $20.17 \%$ of the total conservation priority areas, respectively. As an efficient kind of ecological land with multiple ecosystem services, 458 woodland had been mostly identified as conservation priority areas, with an area 459 proportion of $88.98 \%$. Because of the focus on water ecosystem services in this study, 460 more than $95 \%$ water bodies were identified as conservation priority areas. Although 461 having a high area proportion in total land area of $38.69 \%$, paddy fields and fish ponds 
only covered $20.17 \%$ of the conservation priority areas. In addition, including beach

463 and bare land with high water ecosystem services, $38.92 \%$ unused land was also

464 identified as conservation priority areas. That was to say, water body, wood land, unused

465 land, and paddy field and fish pond had the top priority for ecological conservation in

466 Zhuhai City, due to their importance in supplying water ecosystem services.

467 [figure 7 is here]

468 According to the topographical features of Zhuhai City, the areas with the elevation 469 less than $25 \mathrm{~m}, 25-60 \mathrm{~m}, 60-200 \mathrm{~m}$, and 200-600 m were classified as plains, hills, low 470 mountains and high mountains, respectively. Through comparing the area proportion of 471 topographical types in conservation priority areas, and that of topographical types 472 identified as conservation priority areas, elevation differentiation of conservation 473 priority areas was investigated (Figure 8). As the most common terrain in Zhuhai City, 474 the plains occupied $57.65 \%$ of the conservation priority areas. However, as low as $37.87 \%$ 475 of all the plains were covered in conservation priority areas, which might be due to the 476 high importance of woodland in supplying ecosystem services and its low distribution 477 in the plains. Considering the high suitability for construction, conservation priority 478 areas in the plains were in face with severe human disturbance, and the trade-offs 479 between economic development and ecological conservation usually occurred in land 480 use policy. On the contrary, hills, low mountains and high mountains occupied only a 481 small proportion of the conservation priority areas, accounting for $13.18 \%, 23.70 \%$ and $4825.47 \%$ respectively. However, almost all were included in the conservation priority 483 areas with the ascending order of their conservation proportion. This was mainly 484 because of the increasing woodland coverage and intensified vegetation activity, along 485 with the elevation rising.

486 [figure 8 is here] 


\subsection{Limitations and future research directions}

488 Although quantification is an obvious advantage compared to studies focusing on the 489 identification of spatial pattern of ecosystem services (Peng et al., 2018a, Peng et al., 490 2018b), there are still some limitations needing further improvement in this study. 491 Firstly, spatial distributions of three kinds of service land were obtained based on the 492 simple overlaying of various key areas supplying ecosystem services, with equally 493 weighting of each kind of ecosystem services. In fact, the weights of the specific 494 ecosystem service might be different, slightly or obviously, especially considering 495 potential difference in human preference and thus ecosystem services trade-offs in 496 policy making. Accordingly, weighting issue also lied in the overlying of different 497 service land maps to obtain the map of conservation priority areas.

498 In addition, this study was conducted based on human demanding for ecosystem 499 services. Although it considered the dynamic process of human development, the 500 proposed identification approach was a kind of prediction based on static data in 501 temporal dimension. More dynamic data should be introduced as regards ecological 502 processes. Moreover, the timeliness and uncertainty of multivariate data should be 503 focused on in future studies.

\section{Conclusions}

505 Although demand quantification is an obvious advantage compared with studies 506 focusing on the identification of spatial pattern of ecosys- tem services (Peng, Yang, et 507 al., 2018; Peng, Pan, Liu, Zhao, \& Wang, 2018), there are still some limitations needing 508 further improvement in this study. First, spatial distributions of three kinds of service 509 land were obtained based on the simple overlaying of various key areas supplying 
ecosystem services, with equal weighting of each kind of ecosystem services. In fact,

511 the weights of the specific ecosystem service might be different, slightly or obviously,

512 especially considering potential difference in human preference and thus ecosystem

513 services trade- offs in policy making. Accordingly, weighting issue also lied in the

514 overlying of different service land maps to obtain the map of conservation priority areas.

515 In addition, this study was conducted based on human demand for ecosystem services.

516 Although it considered the dynamic process of human development, the proposed

517 identification approach was a kind of prediction based on static data in temporal

518 dimension. More dynamic data should be introduced as regards ecological processes.

519 Moreover, the timeliness and uncertainty of multivariate data should be focused on in 520 future studies.

\section{References}

523 Ajmal, M., Moon, G. W., Ahn, J. H., \& Kim, T. W. (2015). Investigation of SCS-CN and its inspired 524 modified models for runoff estimation in South Korean watersheds. Journal of Hydro525 environment Research, 9(4), 592-603.

526 Alberti, M. (1999). Modeling the urban ecosystem: a conceptual framework. Environmental and 527 Planning B, 26(4), 623-646.

528 Bai, Y., Wong, C. P., Jiang, B., Hughes, A. C., Wang, M., \& Wang, Q. (2018) Developing China’s 529 Ecological Redline Policy using ecosystem services assessments for land use planning. Nature $530 \quad$ Communications, $9,3034$.

531 Bajocco, S., Angelis, A. D., Perini, L., Ferrara, A., \& Salvati, L. (2012). The Impact of Land 532 Use/Land Cover Changes on Land Degradation Dynamics: A Mediterranean Case Study. 533 Environmental Management, 49, 980-989.

534 Bassett, D. R. J. R., Cureton, A. L., \& Ainsworth, B. E. (2000). Measurement of daily walking 535 distance-questionnaire versus pedometer. Medicine and Science in Sports and Exercise, 32(5), $536 \quad 1018-1023$. 
537 Bergsten, A., Galafassi, D., \& Bodin, Ö. (2014). The problem of spatial fit in social-ecological 538 systems: detecting mismatches between ecological connectivity and land management in an urban 539 region. Ecology \& Society, 19(4), 115-131.

540 Capotorti, G., Vico, E. D., Anzellotti, I., \& Celesti-Grapow, L. (2016). Combining the conservation 541 of biodiversity with the provision of ecosystem services in urban green infrastructure planning: 542 critical features arising from a case study in the metropolitan area of Rome. Sustainability, 9(1), $543 \quad 10$

544 Capps, K. A., Bentsen, C. N., \& Ramírez, A. (2016). Poverty, urbanization, and environmental 545 degradation: urban streams in the developing world. Freshwater Science, 35(1), 429-435.

546 Cheng, X., Chen, L., Sun, R., \& Kong, P. (2018). Land use changes and socio-economic 547 development strongly deteriorate river ecosystem health in one of the largest basins in China. Science of the Total Environment, 616-617, 376-385.

549 Fan, F., Deng, Y., Hu, X., \& Weng, Q. (2013). Estimating composite curve number using an 550 improved SCS-CN method with remotely sensed variables in Guangzhou, China. Remote Sensing, $5(3), 1425-1438$.

552 Fan, M., Shibata, H., \& Wang, Q. (2016). Optimal conservation planning of multiple hydrological 553 ecosystem services under land use and climate changes in Teshio river watershed, northernmost of Japan. Ecological Indicators, 62, 1-13.

555 Farooqui, T. A., Renouf, M. A., \& Kenway, S. J. (2016). A metabolism perspective on alternative 556 urban water servicing options using water mass balance. Water Research, 106, 415-428.

557 Felipe-Lucia, M. R., Comín, F. A., \& Bennett, E. M. (2014). Interactions among ecosystem services 558 across land uses in a floodplain agroecosystem. Ecology \& Society, 19(1), 360-375.

559 Fu, B., Zhao, W., Chen, L., Zhang, Q., Lu, Y., Gulinck, H., \& Poesen, J. (2005). Assessment of soil 560 erosion at large watershed scale using RUSLE and GIS: a case study in the Loess Plateau of China. $561 \quad$ Land Degradation and Development, 16, 73-85.

562 Fu, H., \& Chen, J. (2017). Formation, features and controlling strategies of severe haze-fog 563 pollutions in China. Science of the Total Environment, 578, 121-138.

564 Galdino, S., Sano, E. E., Andrade, R. G., Grego, C. R., Nogueira, S. F., Bragantini, C., \& Flosi, A. 565 H. G. (2016). Large- scale modeling of soil erosion with RUSLE for conservationist planning of 

http://doi.org/10.1002/ldr.2414

Gong, M., Fan, Z., Wang, J., Liu, G., \& Lin, C. (2017). Delineating the ecological conservation redline based on the persistence of key species: Giant pandas (Ailuropoda melanoleuca) inhabiting the Qinling Mountains. Ecological Modelling, 345(10), 56-62.

Guo, B., Yang, G., Zhang, F., Han, F., \& Liu, C. (2018). Dynamic monitoring of soil erosion in the upper Minjiang catchment using an improved soil loss equation based on remote sensing and geographic information system. Land Degradation and Development, 29(3), 521-533.

Heras, M. M. L., Saco, P. M., Willgoose, G. R., \& Tongway, D. J. (2011). Assessing landscape structure and pattern fragmentation in semiarid ecosystems using patch- size distributions. Ecological Applications, 21(7), 2793-2805.

Kingsford, R. T., Biggs, H. C., \& Pollard, S. R. (2011). Strategic Adaptive Management in freshwater protected areas and their rivers. Biological Conservation, 144(4), 1194-1203.

Kinnell, P. I. A. (2010). Runoff dependent erosivity and slope length factors suitable for modeling annual erosion using the Universal Soil Loss Equation. Hydrological Processes, 21(20), 26812689.

Kong, F., Sun, C., Liu, F., Yin, H., Jiang, F., Pu, Y., ... Dronova, I. (2016). Energy saving potential of fragmented green spaces due to their temperature regulating ecosystem services in the summer. Applied Energy, 183, 1428-1440.

Li, C., Zheng, H., Li, S., Chen, X., Li, J., Zeng, W., ... Daily, G. C. (2015). Impacts of conservation and human development policy across stakeholders and scales. Proceedings of the National Academy of Sciences of the United States of America, 112(24), 7396.

Li, H., Peng, J., Liu, Y., \& Hu, Y. (2017a). Urbanization impact on landscape patterns in Beijing City, China: A spatial heterogeneity perspective. Ecological Indicators, 82, 50-60.

591 surface urban heat islands: A case study of Shanghai, China. Remote Sensing of Environment, 115(12), 3249-3263.

593 Li, J., \& Zhou, Z. (2015). Coupled analysis on landscape pattern and hydrological processes in 594 Yanhe watershed of China. Science of the Total Environment, 505, 927-938. 
Li, W., Wang, D., Li, H., \& Liu, S. (2017b). Urbanization-induced site condition changes of peri-

596 urban cultivated land in the black soil region of northeast China. Ecological Indicators, 80, 215223.

598 Li, Y., Qiu, J., Zhao, B., Pavao-Zuckerman, M., Bruns, A., Qureshi, S., ... Li, Y. (2017). Quantifying 599 urban ecological governance: a suite of indices characterizes the ecological planning implications of rapid coastal urbanization. Ecological Indicators, 72, 225-233.

601 Li, Y., Sun, X., Zhu, X., \& Cao, H. (2010). An early warning method of landscape ecological 602 security in rapid urbanizing coastal areas and its application in Xiamen, China. Ecological 603 Modelling, 221(19), 2251-2260.

604 Lin, B. B., Egerer, M. H., Liere, H., Jha, S., Bichier, P., \& Philpott, S. M. (2018). Local-and 605 landscape-scale land cover affects microclimate and water use in urban gardens. Science of the Total Environment, 610-611, 570.

607 Lin, K., Lv, F., Chen, L., Singh, V. P., Zhang, Q., \& Chen, X. (2014). Xinanjiang model combined 608 with Curve Number to simulate the effect of land use change on environmental flow. Journal of Hydrology, 519, 3142-3152.

610 Lin, Q., Mao, J., Wu, J., Li, W., \& Yang, J. (2016). Ecological security pattern analysis based on 611 InVEST and least-cost path model: a case study of Dongguan water village. Sustainability, 8(2), $612 \quad 172$.

613 Liu, Q. Q., Xiang, H., \& Singh, V. P. (2010). A simulation model for unified interrill erosion and rill 614 erosion on hillslopes. Hydrological Processes, 20(3), 469-486.

615 Łopucki, R., \& Kiersztyn, A. (2015). Urban green space conservation and management based on 616 biodiversity of terrestrial fauna-a decision support tool. Urban Forestry \& Urban Greening, 14(3), $617 \quad 508-518$.

618 Martin-Ortega, J., Ojea, E., \& Roux, C. (2013). Payments for water ecosystem services in Latin 619 America: a literature review and conceptual model. Ecosystem Services, 6, 122-132.

620 McPhearson, T., Kremer, P., \& Hamstead, Z. A. (2013). Mapping ecosystem services in New York 621 City: applying a social-ecological approach in urban vacant land. Ecosystem Services, 5, 11-26. 622 Moore, T. L. C., \& Hunt, W. F. (2012). Ecosystem service provision by stormwater wetlands and 623 ponds - A means for evaluation?. Water Research, 46(20), 6811-6823. 
Mulatu, D. W., Veen, A. V. D., \& Oel, P. R. V. (2014). Farm households' preferences for collective and individual actions to improve water-related ecosystem services: the Lake Naivasha basin, Kenya. Ecosystem Services, 7(7), 22-33.

Nakil, M., \& Khire, M. (2016). Effect of slope steepness parameter computations on soil loss estimation: review of methods using GIS. Geocarto International, 31(10), 1078-1093.

Ng, S. L., Leung, Y. F., Cheung, S. Y., \& Fang, W. (2017) Land degradation effects initiated by trail running events in an urban protected area of Hong Kong. Land Degradation and Development, 29, 422-432. http://doi.org/10.1002/ldr.2863

Ólafsdóttir, R., \& Júlíusson, Á. D. (2015). Farmers' perception of land- cover changes in NE Iceland. Land Degradation and Development, 11(5), 439-458. https://doi.org/10.1002/1099145X(200009/10)11:5<439::AID-LDR406>3.0.CO;2-K

Oliveira, Eduardo., Tobias, Silvia., \& Hersperger, A. M. (2018). Can Strategic Spatial Planning Contribute to Land Degradation Reduction in Urban Regions? State of the Art and Future Research. Sustainability, 10, 949.

Panagos, P., Borrelli, P., Meusburger, K., Zanden, E. H. V .D., Poesen, J., \& Alewell, C. (2015). Modelling the effect of support practices (P-factor) on the reduction of soil erosion by water at European scale. Environmental Science \& Policy, 51, 23-34.

Peng, J., Pan, Y., Liu, Y., Zhao, H., \& Wang, Y. (2018b). Linking ecological degradation risk to identify ecological security patterns in a rapidly urbanizing landscape. Habitat International, 71, $110-124$.

Peng, J., Yang, Y., Liu, Y., Hu, Y., Du, Y., Meersmans, J., \& Qiu, S. (2018a). Linking ecosystem services and circuit theory to identify ecological security patterns in Yunnan Province, China. Science of the Total Environment, 644, 781-790.

Peng, J., Zhao, M., Guo, X., Pan, Y., \& Liu, Y. (2017). Spatial-temporal dynamics and associated driving forces of urban ecological land: a case study in Shenzhen City, China. Habitat International, 60, 81-90.

Peng, J., Zong, M., Hu, Y. N., Liu, Y., \& Wu, J. (2015). Assessing landscape ecological risk in a mining city: a case study in Liaoyuan City, China. Sustainability, 7(7), 8312-8334.

Polyakov, V., Fares, A., Kubo, D., Jacobi, J., \& Smith, C. (2007). Evaluation of a non-point source 

pollution model, AnnAGNPS, in a tropical watershed. Environmental Modelling \& Software, 22(11), 1617-1627.

Posner, S., Verutes, G., Koh, I., Denu, D., \& Ricketts, T. (2016). Global use of ecosystem service models. Ecosystem services, 17, 131-141.

Qiu, T., Song, C., \& Li, J. (2017). Impacts of urbanization on vegetation phenology over the past three decades in Shanghai, China. Remote Sensing, 9(9), 970.

Redhead, J. W., Stratford, C., Sharps, K., Jones, L., Ziv, G., Clarke, D., ... Bullock, J. M. (2016). Empirical validation of the InVEST water yield ecosystem service model at a national scale. Science of the Total Environment, 569-570, 1418-1426.

Runfola, D. M., \& Pontius Jr, R. G. (2013). Measuring the temporal instability of land change using the Flow matrix. International Journal of Geographical Information Science, 27(9), 1696-1716. Runfola, D. M., Ratick, S., Blue, J., Machado, E.A., Hiremath, N., Giner, N., ... Arnold, J. (2017). A multi-criteria geographic information systems approach for the measurement of vulnerability to climate change. Mitig Adapt Strateg Glob Change, 22, 349-368.

Snäll, T., Lehtomäki, J., Arponen, A., Elith, J., \& Moilanen, A. (2016). Green Infrastructure design based on spatial conservation prioritization and modeling of biodiversity features and ecosystem services. Environmental Management, 57(2), 251-256.

Taye, G., Vanmaercke, M., Poesen, J., Wesemael, B. V., Tesfaye, S., Teka, D., ... Haregeweyn, N. (2017). Determining RUSLE P- and C-factors for stone bunds and trenches in rangeland and cropland, North Ethiopia. Land Degradation and Development, 29(3), 812-824.

Thomas, D. S. G., Sporton, D., \& Perkins, J. (2015). The environmental impact of livestock ranches in the Kalahari, Botswana: natural resource use, ecological change and human response in a dynamic dryland system. Land Degradation and Development, 11(4), 327-341. https://doi.org/10.1002/1099-145X(200007/08)11:4<327::AID-LDR395>3.0.CO;2-V

Vettorazzi, C. A., \& Valente, R. A. (2016). Priority areas for forest restoration aiming at the conservation of water resources. Ecological Engineering, 94, 255-267.

Xu, J., Zhao, Y., Zhong, K., Ruan, H., \& Liu, X. (2016). Coupling modified linear spectral mixture analysis and Soil Conservation Service Curve Number (SCS-CN) models to simulate surface runoff: application to the main urban area of Guangzhou, China. Water, 8(12), 550. 
682 Yang, L., Zhang, L., Li, Y., \& Wu, S. (2015). Water-related ecosystem services provided by urban 683 green space: a case study in Yixing City (China). Landscape \& Urban Planning, 136, 40-51.

684 Zhang, L., Peng, J., Liu, Y., \& Wu, J. (2017). Coupling ecosystem services supply and human 685 ecological demand to identify landscape ecological security pattern: a case study in Beijing686 Tianjin-Hebei region, China. Urban Ecosystems, 20(3), 1-14.

687 Zheng, H., Li, Y., Robinson, B. E., Liu, G., Ma, D., Wang, F., ... Daily, G. C. (2016). Using 688 ecosystem service trade- offs to inform water conservation policies and management practices. 689 Frontiers in Ecology \& the Environment, 14(10), 527

690

691 Acknowledgements: This research was financially supported by the National Natural 692 Science Foundation of China (No. 41271195), and the 111 Project (B14001). 693 694 
697 Figure 1 The geographical location of Zhuhai City

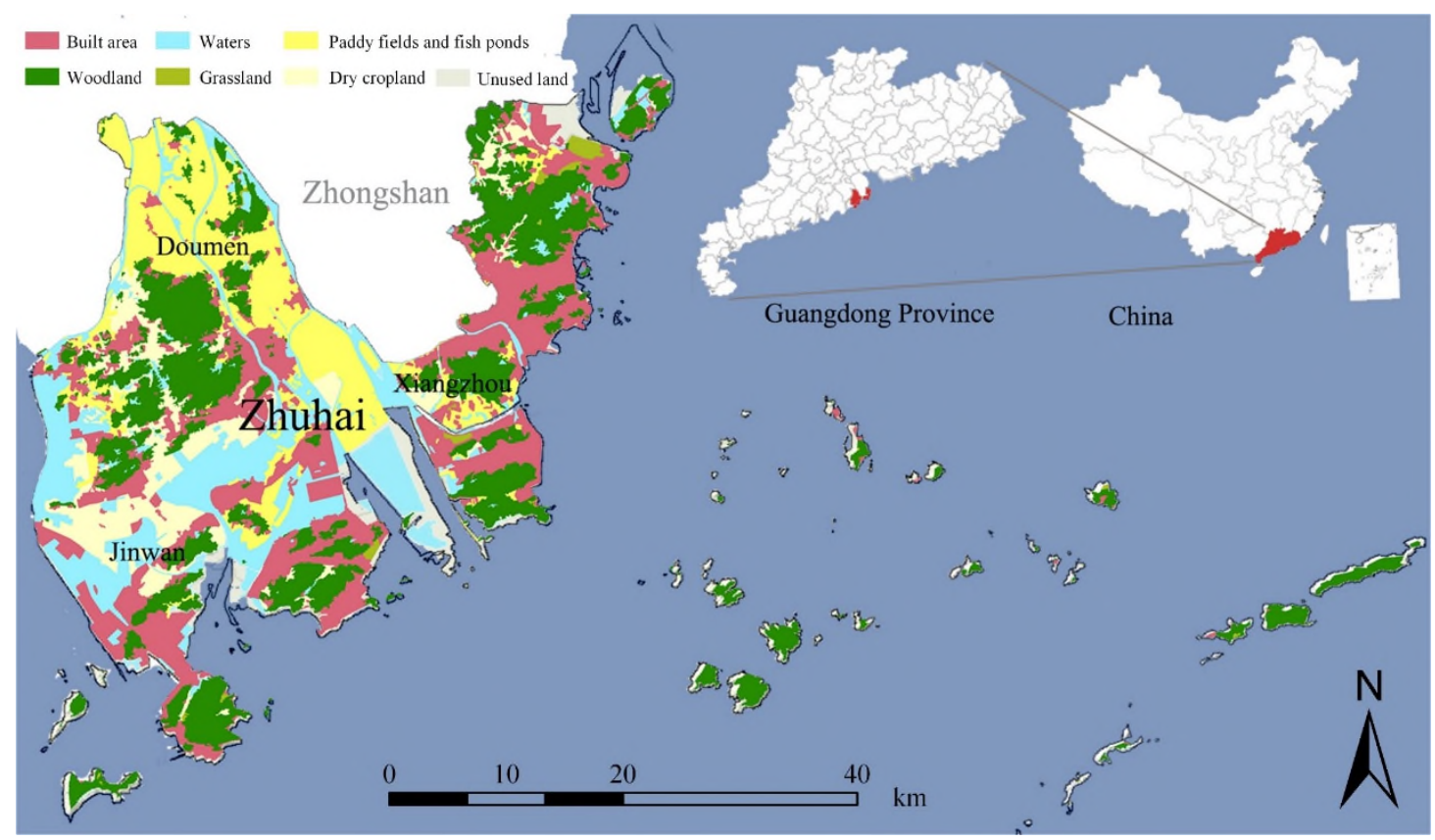

701 Figure 2 Research framework for identifying the conservation priority area and 702 management zoning for urban ecological land

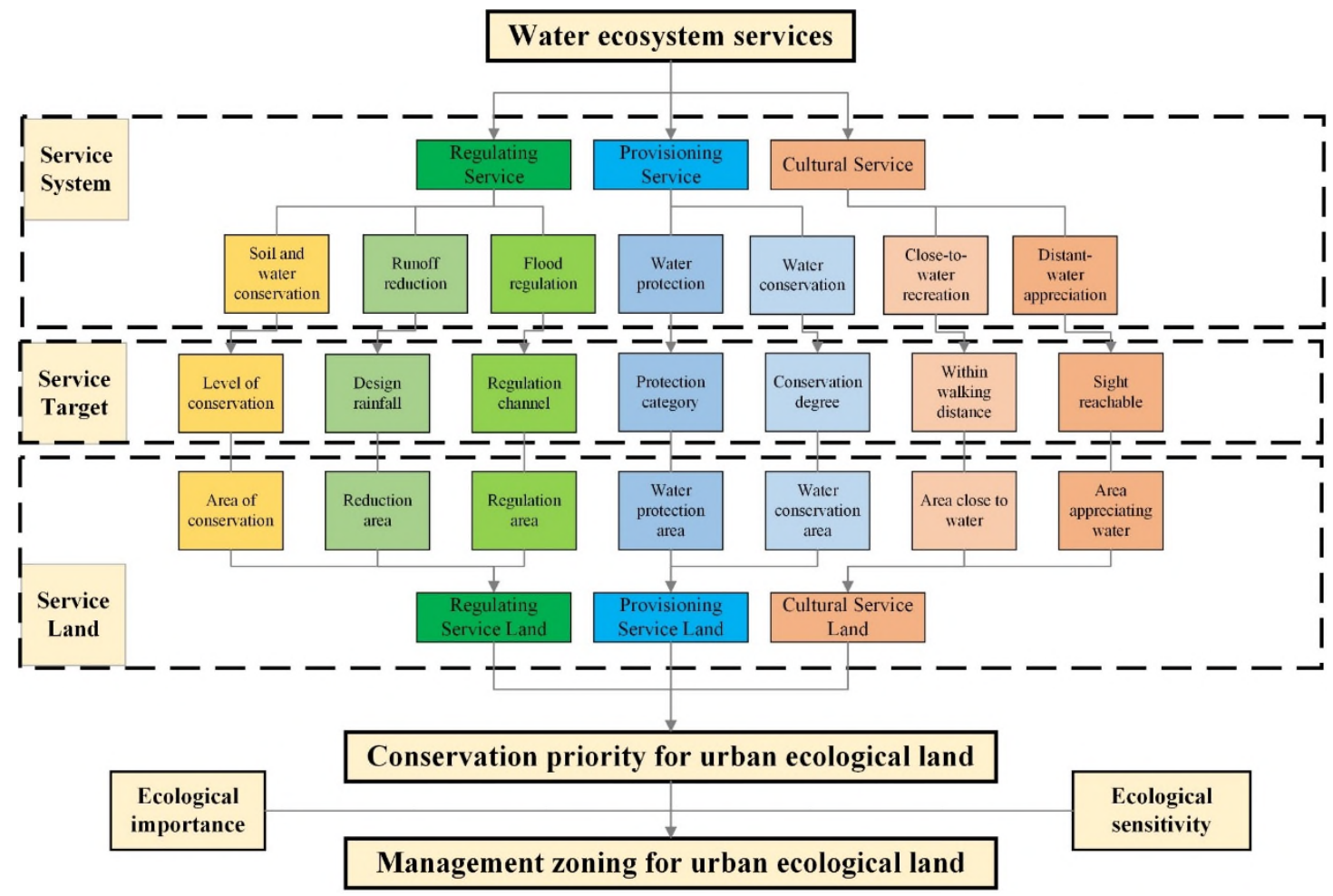


705 Figure 3 Spatial distribution of key areas for water ecosystem services in Zhuhai City.

706 a) Soil retention area; b) Runoff reduction area; c) Flood regulation area; d) Water 707 protection area; e) Water conservation area; f) Water recreation area; g) Water 708 appreciation area.

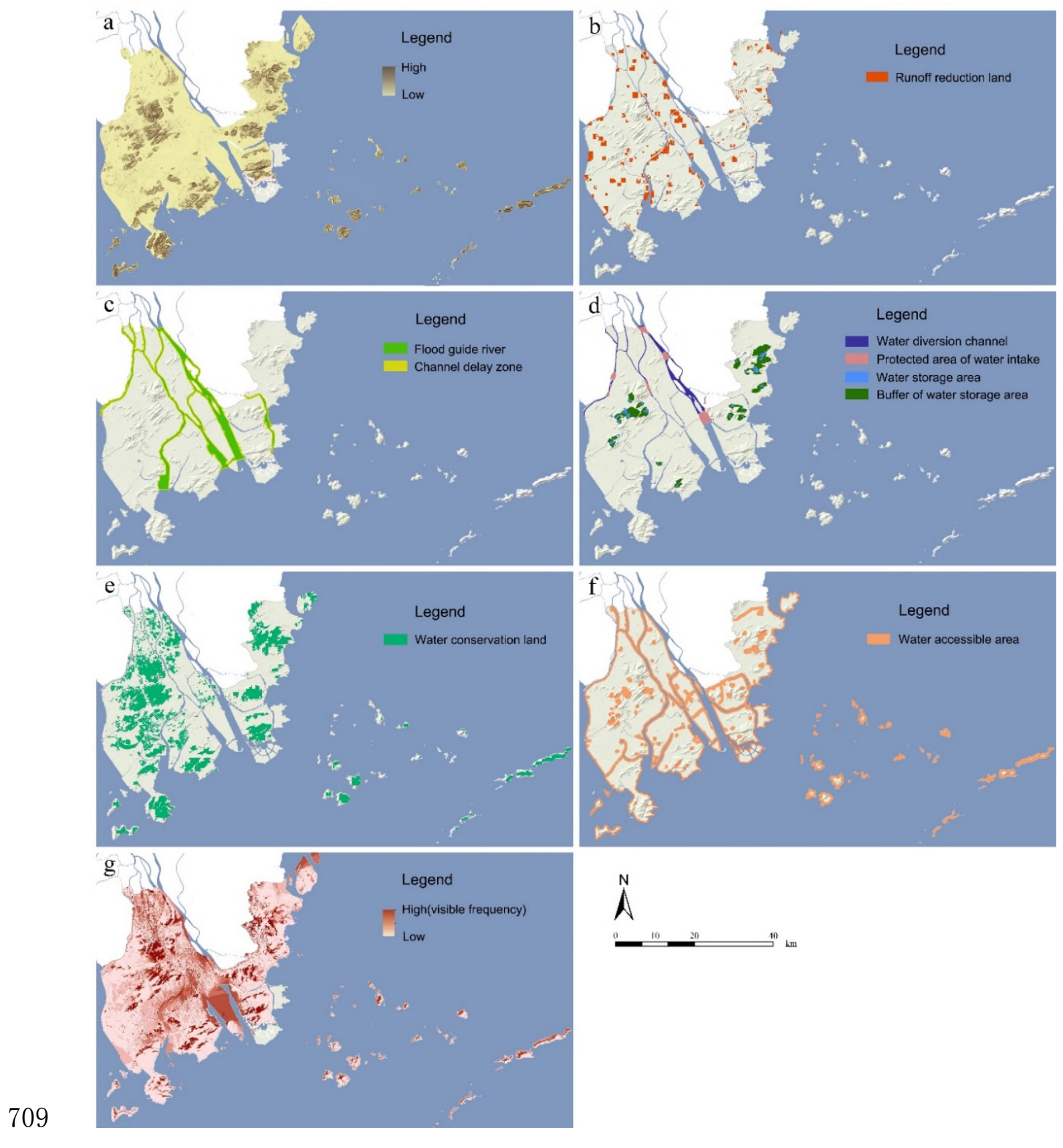


711 Figure 4 Spatial distribution of water ecosystem service land in Zhuhai City.

712 a) Regulating service land; b) Provisioning service land; c) Cultural service land

713 Figure 5 Conservation priority areas for urban ecological land in Zhuhai City
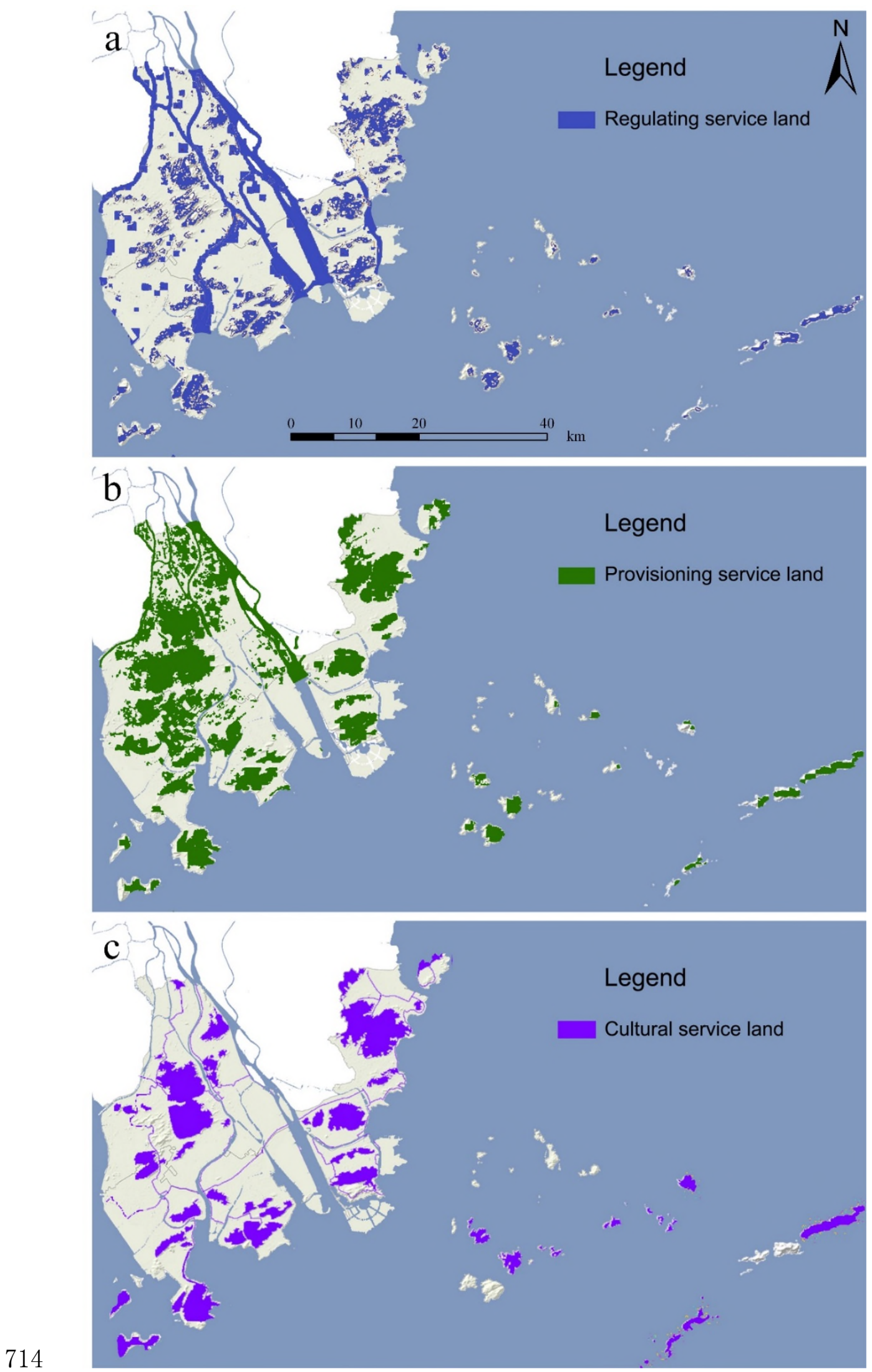
715 Figure 6 Management zoning for urban ecological land in Zhuhai City. a) Ecological

716 importance; b) Ecological sensitivity; c) Management zoning

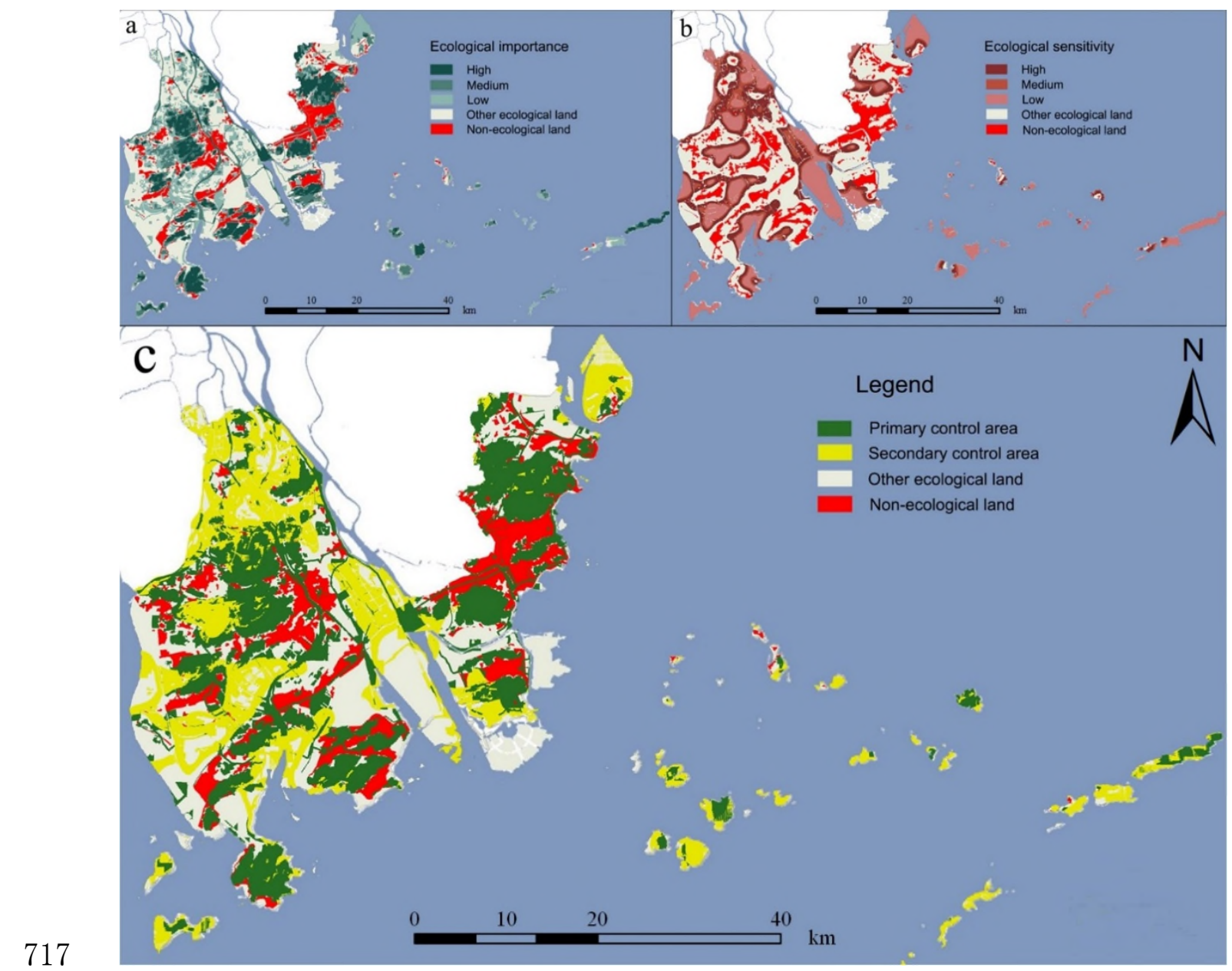

718

719 Figure 7 Area proportion contrast of land use types in the conservation priority area
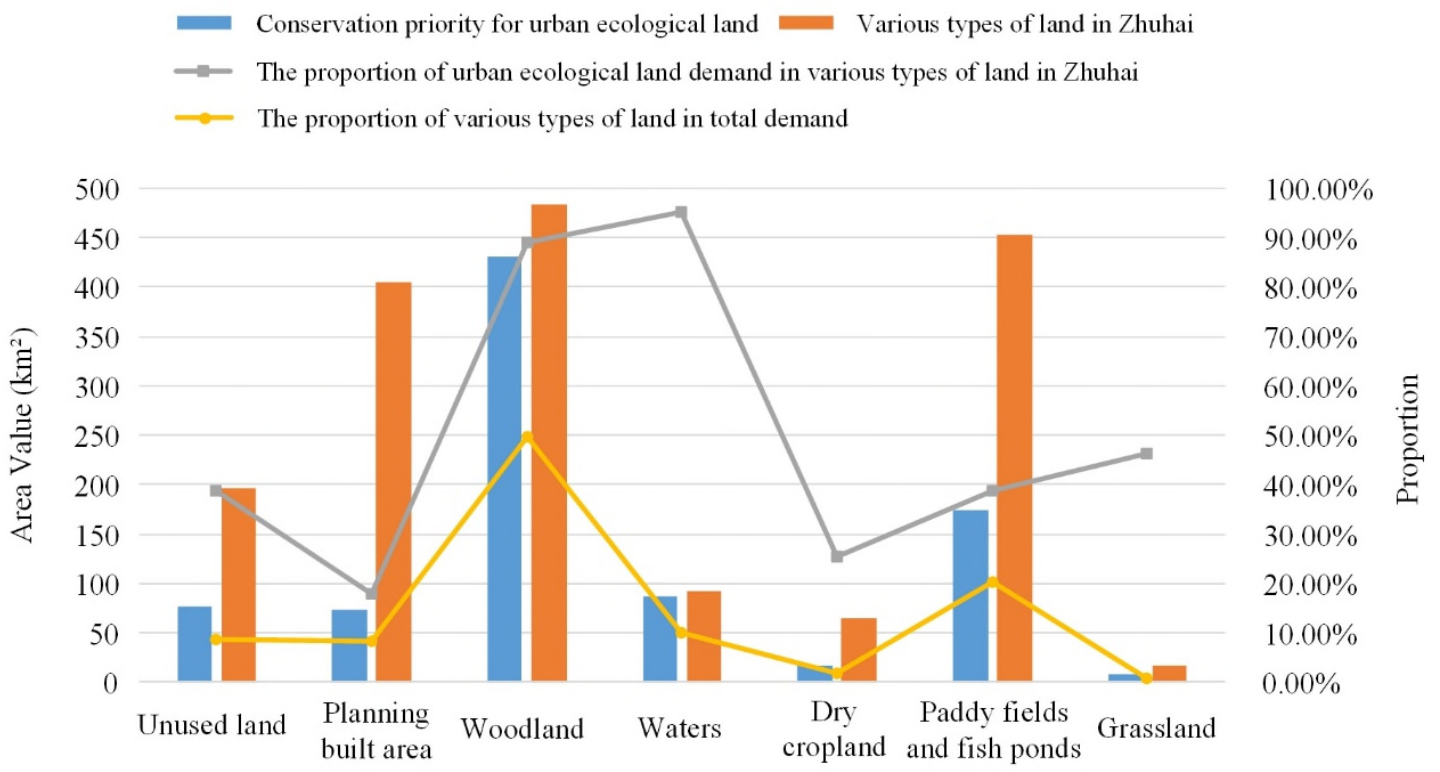

area

724

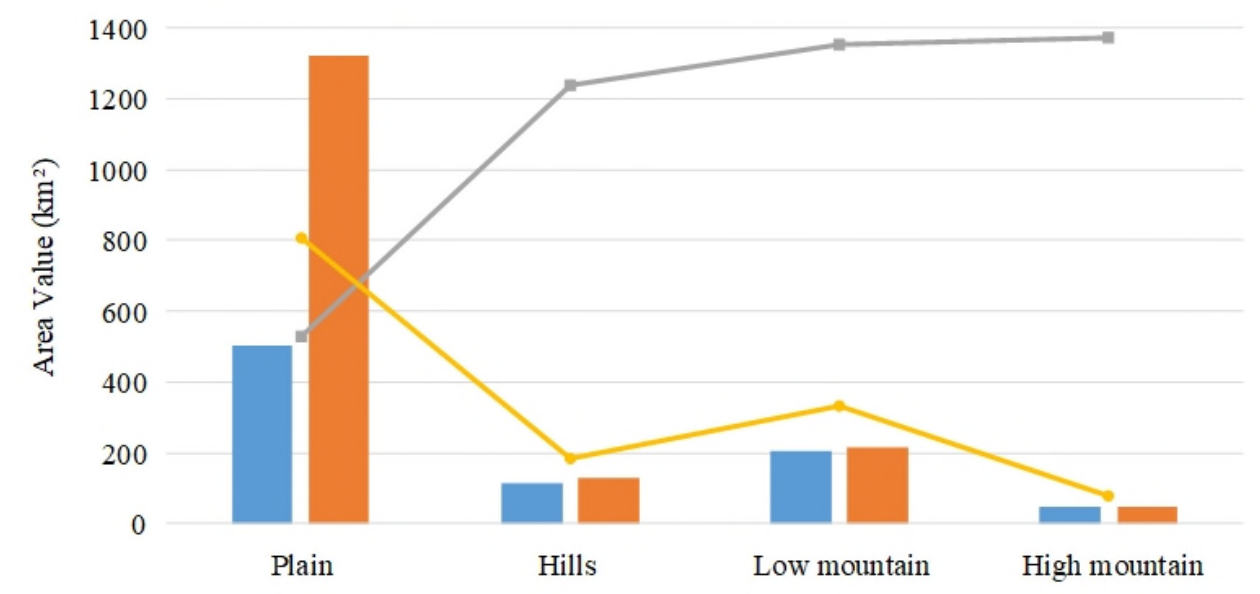

$100.00 \%$

$90.00 \%$

$80.00 \%$

$70.00 \%$

$60.00 \%$

$50.00 \%$

$40.00 \%$

$30.00 \%$

$20.00 \%$

$10.00 \%$

$0.00 \%$

727 Table 1 Sensitivity coefficient of ecological land

728 
Table 1. Sensitivity coefficient of ecological land.

\begin{tabular}{lllllllll}
\hline \multirow{2}{*}{$\begin{array}{lllllll}\text { Sensitive } \\
\text { source }\end{array}$} & $\begin{array}{l}\text { Sensitive } \\
\text { distance }\end{array}$ & Sensitivity & \multicolumn{5}{c}{ Sensitivity coefficient } \\
\cline { 6 - 9 } & $(\mathrm{km})$ & weight & Woodland & Water body & $\begin{array}{l}\text { Dry } \\
\text { cropland }\end{array}$ & $\begin{array}{l}\text { Paddy } \\
\text { and fish pond }\end{array}$ & Grassland & Unused land \\
\hline Urban area & 6 & 1 & 0.8 & 0.8 & 1 & 1 & 0.8 & 1 \\
Town & 4 & 0.8 & 0.7 & 0.7 & 0.8 & 0.8 & 0.7 & 1 \\
Village & 3 & 0.5 & 0.5 & 0.5 & 0.3 & 0.3 & 0.5 & 0.5 \\
Road & 4 & 0.6 & 0.7 & 0.7 & 0.9 & 0.9 & 0.8 & 0.9 \\
Railway & 2 & 0.3 & 0.3 & 0.3 & 0.5 & 0.5 & 0.5 & 0.5 \\
\hline
\end{tabular}

